\title{
Elevated levels of serum IL-5 are associated with an increased likelihood of major depressive disorder
}

\author{
Antti-Pekka Elomaa ${ }^{1 *}$, Leo Niskanen² ${ }^{2}$ Karl-Heinz Herzig ${ }^{1,3}$, Heimo Viinamäki ${ }^{1}$, Jukka Hintikka', \\ Heli Koivumaa-Honkanen ${ }^{1,4,5}$, Kirsi Honkalampi ${ }^{6}$, Minna Valkonen-Korhonen ${ }^{1}$, Ilkka T Harvima ${ }^{7}$ and Soili M Lehto
}

\begin{abstract}
Background: Inflammatory mediators in both the peripheral circulation and central nervous system (CNS) are dysregulated in major depressive disorder (MDD). Nevertheless, relatively little is known about the role of the T-helper (Th)-2 effector cytokines interleukin (IL)-5 and IL-13 in MDD.

Methods: We examined the serum levels of these cytokines and a Th-1 comparison cytokine, interferon (IFN)- $\gamma$, in 116 individuals ( $M D D, n=58$; controls, $n=58$ ).

Results: In our basic multivariate model controlling for the effects of potential confounders on the associations between MDD and the examined cytokines, each 1-unit increase in the serum IL-5 level increased the likelihood of belonging to the MDD group by $76 \%(\mathrm{OR} 1.76,95 \% \mathrm{Cl} 1.03-2.99, \mathrm{p}=0.04$; model covariates: age, gender, marital status, daily smoking and alcohol use). The likelihood further increased in models additionally controlling for the effects of the use of antidepressants and NSAIDS, and a diagnosis of asthma. No such associations were detected with regard to IL-13 (OR 1.08, 95\% Cl 0.96-1.22, $\mathrm{p}=0.22$ ) or IFN- $\gamma(\mathrm{OR} 1.02,95 \% \mathrm{Cl} 0.99-1.05, \mathrm{p}=0.23)$.

Conclusions: Elevated levels of IL-5, which uses the neural plasticity-related RAS GTPase-extracellular signalregulated kinase (Ras-ERK) pathway to mediate its actions in the central nervous system (CNS), could be one of the factors underlying the depression-related changes in CNS plasticity.
\end{abstract}

\section{Background}

According to the monocyte-T-lymphocyte hypothesis of major depression, the pathophysiology of major depressive disorder (MDD) anticipates immune system activation [1]. Cytokines are immune system signaling molecules that affect the synthesis, release, and cell reuptake of monoamines [2]. Both their absence and overexpression affects central nervous system functions such as synaptic plasticity, neurogenesis, and neuromodulation in varying ways, including activity within basal ganglia and the frontal cortex [3-6]. They also modulate the activity of the hypothalamus-pituitary axis (HPA), which is a central factor in the pathogenesis of MDD [7].

\footnotetext{
* Correspondence: apelomaa@gmail.com

'Department of Psychiatry, Kuopio University Hospital and University of Eastern Finland, Kuopio, Finland

Full list of author information is available at the end of the article
}

Several studies have indicated MDD as an inflammatory state with elevated levels of proinflammatory cytokines [e.g. Interleukin (IL)- 6 and -12 and interferon (IFN)- $\gamma$ ] [8]. Cytokines such as IL-1 and tumor necrosis factor (TNF)- $\alpha$ are also dysregulated, and they have been suggested to serve as neuroplasticity-modulating factors in MDD neuropathology [9]. Moreover, much emphasis has been placed on the imbalance between T-helper (Th) cell cytokines Th1 and Th2 in the pathogenesis of MDD [10]. While MDD is linked to disturbance in the homeostasis of immune systems [7,11], it also increases the likelihood of several somatic conditions such as cardiovascular diseases, diabetes, and cancer [12], as well as asthma and other allergic conditions [13]. In particular, asthmatic adolescents have a significantly increased risk of the early development of psychiatric disorders, while MDD patients with comorbid asthma suffer from greater impairments in asthma symptoms [14].

\section{() Biomed Central}


Th cells regulate the immune systems through the production of cytokines [15]. Th cells are mainly divided into two types according to their polarization. Th1 cells regulate cell-mediated immune responses and are characterized by IL- 2 and IFN- $\gamma$ production [16]. IFN- $\gamma$ has various immunoregulatory actions. Its biological responses are closely integrated with the other cytokine mechanisms, with signaling pathways especially cross-talking with IFN- $\alpha$ [17]. IFN- $\gamma$ is one of most studied cytokines in MDD [18]. Th2 cells regulate humoral immunity via B-cell actions by producing IL-4, IL-5, and IL-13 [19]. Furthermore, other T-cells such as Th17 and regulatory $\mathrm{T}$-cells have emerged as important factors controlling immune responses and inflammation [20].

Cytokines IL-5 and IL-13 play important roles in the pathophysiology of various autoimmune diseases such as asthma [21] and Graves' disease [22]. IL-4 mainly functions by activating Th2 cells, while IL- 5 and IL-13 work as effector cytokines of activated Th2 cells, i.e. they are secreted by Th cells after the cells are activated [23]. Elevated levels of IL-13 and lower levels of IFN- $\gamma$ have been associated with MDD [24]. Interestingly, possible routes between IL- 5 and MDD have also been stated. There is a genetic risk for MDD through the colony stimulating factor 2 receptor $\beta$ (CSF2RB) haplotype, which encodes a protein in high affinity receptors binding IL-5 [25]. Furthermore, a gene set analysis of post-mortem brain tissue has suggested the upregulation of IL-5 levels in MDD [26]. However, to the best of our knowledge, there have been very few studies examining IL-5 and IL-13 in relation to MDD.

The goal of this study was to examine the roles of the Th2 effector cytokines IL-5 and IL-13 and an established comparison Th1 cytokine, IFN- $\gamma$, in MDD. While IL-4 has been intensively studied with regard to MDD, increasing evidence has accumulated of the roles of other Th2 cytokines in contributing to neuromodulatory alterations similar to those observed in MDD (e.g., impaired neuroplasticity). Thus, individuals with MDD would be likely to show elevations in the secretion of these cytokines. IFN- $\gamma$ was chosen because of its central relationship with MDD, and due to its comparative role to the Th2 cytokines as a Th1 cytokine.

\section{Methods}

The study was conducted as part of the Kuopio Depression (KUDEP) four-phase general population study involving adults aged 25-64 years in the province of Kuopio in Eastern Finland. A random sample of 3004 participants was selected in 1998 from the National Population Register and was followed up in 1999 and 2001. The baseline sample included 2050 participants, the first follow-up sample (1999) 1722 participants, and the second follow-up sample (2001) 1593 participants. The second follow-up questionnaire was only sent to those subjects who responded in either of the preceding surveys. Questionnaires were re-sent to the non-respondents one month later after each follow-up. Participants responded to questions concerning their age, gender, marital status (married or living with a partner vs. living alone), asthma diagnosis by a physician (yes vs. no), daily smoking (yes vs. no), alcohol use ( $\geq 2$ times per week vs. less), and the use of antidepressant medications (yes vs. no).

In 2005, a sub-sample of 427 participants from the previous study phases reporting either high or low levels of adverse mental symptoms were asked to take part in a clinical evaluation and laboratory testing $[27,28]$ as a fourth study phase. For the present study, we selected those participants whose Beck Depression Inventory (BDI) [29] scores indicated depressive symptoms (BDI scores $\geq$ 10 ; depressed) or a euthymic state (BDI scores $\leq 9$; controls) consistently at all three earlier data collection points. The mean BDI scores (standard deviation, SD) for the depressed $(\mathrm{n}=58)$ were 18.1 (9.1) in 1998, 21.5 (9.9) in 1999 , and 20.9 (11.1) in 2001. The corresponding means (SD) for the controls $(n=58)$ were $2.6(2.2)$ in 1998, 2.9 (2.6) in 1999, and 2.1 (1.9) in 2001.

Psychiatric interviews were conducted for all participants, including the controls, by a trained, experienced research nurse using the Structured Clinical Interview for DSM-IV (SCID-I and SCID-II) [30-32]. Additionally, the 29-item Hamilton Depression Rating Scale (HAM-D-29) [33] was used for the assessment of depression severity. The HAM-D-29 includes the 21-item Hamilton Depression Rating Scale (HAM-D-21) with a supplementary 8item subscale (Atypical Depression Supplement, ADS) for measuring atypical features of depression. The ADS includes questions regarding weight gain, increased appetite/eating, carbohydrate craving, hypersomnia, leaden paralysis, and social withdrawal. Subjects with bipolar disorders were excluded and the primary diagnosis for all the rest of the depressed participants was MDD. Data concerning the participants' somatic medications were acquired from the nationwide Social Insurance Institute. Approval for the study was obtained from the Ethics Committee of Kuopio University Hospital and the University of Eastern Finland. The study protocol was in accordance with the Declaration of Helsinki. All participants provided written informed consent before entering the study.

After the clinical interviews, the participants were given a referral to the laboratory, and were then instructed to visit the laboratory at the latest during the following week. The body mass index $\left(\mathrm{kg} / \mathrm{m}^{2}\right)$ was calculated from height and body weight measured in light clothing without shoes. The venous blood serum samples for the cytokine analyses were stored at $-80^{\circ} \mathrm{C}$ until run. IL-5 (pg/ $\mathrm{mL}), \mathrm{IL}-13(\mathrm{pg} / \mathrm{mL})$ and IFN- $\gamma(\mathrm{pg} / \mathrm{mL})$ levels were analyzed by multiplexing with Bio-Plex Human Cytokine 
Panel 1 utilizing a Bio-Plex 200 instrument based on Luminex xMAP technology (Bio-Rad Laboratories Inc., CA, US). The Luminex method and the standard enzyme-linked immunosorbent assay (ELISA) are highly correlated [34-36]. Before analyses, the samples were centrifuged for $15 \mathrm{~min}$ at $3000 \mathrm{rpm}$, and diluted 1:2 in a sample matrix. The samples were assayed singly, and the assay conditions were standardized and pre-optimized to ensure optimal reproducibility of the assays. The kit instructions and instrument manuals were followed accordingly. The intra-assay and interassay variation for the kit analyses were $4.6-13.8 \%$ and $3.7-17.2 \%$, respectively. The results were calculated with BioPlex Manager Software version 4.3 with five-parameter logistic equations [37]. High sensitivity range standard settings were utilized. The values between zero (blank sample) and the lowest standard (IL-5: $0.52 \mathrm{pg} / \mathrm{ml}$;L-13: $0.71 \mathrm{pg} / \mathrm{ml}$; IFN- $\gamma: 0.30 \mathrm{pg} / \mathrm{ml}$ ) were extrapolated from the standard curve by the software. In statistical analyses, the nondetectable samples (ND) were marked as the mean value between zero and the lowest extrapolated value of each cytokine [38]. There were 17 NDs for IL-5, 30 for IL-13, and 52 for IFN- $\gamma$.

The data were analyzed using SPSS version 17.0 statistical software (SPSS Inc., Chicago, IL). Differences between the MDD and control groups were assessed using the chi-squared test for categorical variables, and the Student's t-test and the Mann-Whitney U-test for continuous variables. Parametric tests were used with normally distributed and non-parametric tests with nonnormally distributed variables. The differences between the MDD and control groups in the examined cytokines were further examined with logistic regression modeling. The modeling was performed in two steps. First, we formed a basic model consisting of general parameters either showing differences between the groups or known to affect the levels of IL-5, IL-13 or IFN- $\gamma$ (Model 1: age, gender, marital status, alcohol use [39], and daily smoking [40]). Secondly, for more comprehensive evaluation of the effects of potential confounders, we formed models that included the variables in Model 1 together with further adjustments for one of the following covariates: the use of antidepressants (Model 2), the use of NSAIDs (Model 3), and a diagnosis of asthma (Model 4). The cytokines were inserted into the models as continuous variables. The odds ratios (OR) show the likelihood for each 1-point increase in the serum levels of these cytokines, i.e. OR show the odds for a covariate belonging to the MDD group in relation to the control group.

\section{Results}

The characteristics of the study population are presented in Table 1. The individuals in the MDD group more often lived alone, smoked, and used antidepressant medication.
They also showed higher scores on all the depression scales used in the present study, i.e. HAM-D-21, HAM-D29 , ADS, and BDI. The levels of IL-5, IL-13 and IFN- $\gamma$ did not significantly differ between the groups in the crude analysis. Moreover, scatterplots were formed to visualize the relationships between IL-5 (Figure 1), IL-13 (Figure 2) and IFN- $\gamma$ (Figure 3) and the BDI scores from the 2005 questionnaire.

In the multivariate models (Table 2) controlling for the effects of potential confounders on the associations between depression and the examined cytokines, each 1unit increase in the serum IL-5 levels increased the likelihood of belonging to the MDD group by $76 \%$ (OR 1.76, 95\% CI 1.03-2.99, $\mathrm{p}=0.038$ ) in Model 1 adjusted for age, gender, marital status, daily smoking, and alcohol use. The observations remained essentially similar in the other models further adjusted for the use of antidepressants (Model 2: OR 2.06, 95\% CI 1.16-3.63, p = 0.013), the use of NSAIDS (Model 3: OR 1.89, 95\% CI 1.10-3.27, $\mathrm{p}=0.022$ ) and a diagnosis of asthma (Model 4: OR 1.83, $95 \%$ CI 1.07-3.14, $\mathrm{p}=0.028)$. No such associations were observed for IL-13 or IFN- $\gamma$ (Table 2).

\section{Discussion}

\subsection{Main findings}

The elevation of serum levels of IL- 5 was associated with an increased likelihood for belonging to the group with MDD. No such associations were detected with regard to IL-13 or IFN- $\gamma$.

\subsection{Previous literature}

Previous data on the connections between IL-5 and MDD are scarce. However, a recent post-mortem gene set analysis suggested an up-regulation of IL-5 levels in the frontal cortices of individuals with MDD [26]. Our findings were consistent with this observation, demonstrating similar elevations in circulating levels of IL-5. This is also in line with studies showing elevated levels of other Th2 cytokines, such as IL-4 and IL-13 [41]. On the other hand, a study by Simon et al. (2008) [42] revealed no difference in IL-5 levels between the MDD group and controls. These findings, however, were not adjusted for potential confounders such as smoking, which appears to lower the levels of serum IL-5 [40]. Thus, the lack of adjustment for smoking in the study by Simon et al., as well as in our study with respect to our initial crosssectional association (Table 1), may underlie our observation of only borderline significance for elevated IL-5 levels in MDD.

Elevated levels of IL-13, IFN- $\gamma$, and the Th1/Th2 ratio have been detected in MDD [19]. In our study, the individuals with MDD had higher overall levels of both IL-13 and IFN- $\gamma$, but this difference did not reach statistical significance. However, the small study population of the 
Table 1 The characteristics of the study participants

\begin{tabular}{|c|c|c|c|c|}
\hline & MDD & Controls & & \\
\hline & $\mathrm{n}=58$ & $n=58$ & Statistics* & p-value \\
\hline Age & $53.40 \pm 1.22$ & $53.21 \pm 1.20$ & $t=-0.011$ & $0.912^{\mathrm{a}}$ \\
\hline Female, n (\%) & $40(69.0)$ & $40(69.0)$ & $\chi^{2}=0.00$ & $1.000^{b}$ \\
\hline Married or living with a partner, n (\%) & $48(82.5)$ & $55(94.8)$ & $\chi^{2}=5.25$ & $0.039^{b}$ \\
\hline Daily smoking, n (\%) & $18(31.0)$ & $4(6.9)$ & $\chi^{2}=10.99$ & $0.001^{b}$ \\
\hline Alcohol use, $\geq 2$ times per week (\%) & $9(15.5)$ & $10(17.2)$ & $\chi^{2}=0.06$ & $0.802^{b}$ \\
\hline Asthma, n (\%) & $3(5.2)$ & $5(8.6)$ & $\chi^{2}=0.537$ & $0.464^{b}$ \\
\hline $\mathrm{BMI}\left(\mathrm{kg} / \mathrm{m}^{2}\right)$ & $27.24 \pm 0.86$ & $27.13 \pm 0.65$ & $Z=-0.04$ & $0.967^{c}$ \\
\hline HAM-D-21 & $12.00 \pm 0.73$ & $2.98 \pm 0.36$ & $Z=-8.00$ & $<0.001^{c}$ \\
\hline ADS & $2.84 \pm 0.43$ & $0.59 \pm 0.13$ & $Z=-4.04$ & $<0.001^{c}$ \\
\hline HAM-D-29 & $14.84 \pm 0.99$ & $3.57 \pm 0.41$ & $Z=-7.86$ & $<0.001^{c}$ \\
\hline $\mathrm{BDI}$ & $17.68 \pm 0.97$ & $3.55 \pm 0.41$ & $Z=-8.77$ & $<0.001^{c}$ \\
\hline Use of NSAIDs, n (\%) & $7(12.1)$ & $1(1.7)$ & - & $0.061^{d}$ \\
\hline Use of oral corticosteroids, n (\%) & $5(8.6)$ & $3(5.2)$ & - & $0.717^{d}$ \\
\hline Use of antidepressants, n (\%) & $22(37.9)$ & $4(6.9)$ & $\chi^{2}=16.06$ & $<0.001^{b}$ \\
\hline IL-5 (pg/ml) & $0.81 \pm 0.13$ & $0.54 \pm 0.08$ & $Z=-1.87$ & $0.061^{c}$ \\
\hline IL-13 (pg/ml) & $7.51 \pm 6.05$ & $0.89 \pm 0.22$ & $Z=-0.60$ & $0.549^{c}$ \\
\hline IFN- $\gamma(p g / m l)$ & $12.03 \pm 5.96$ & $3.03 \pm 0.91$ & $Z=-0.43$ & $0.664^{c}$ \\
\hline IFN- $\gamma /$ IL-5 ratio & $6.97 \pm 1.99$ & $24.69 \pm 11.16$ & $Z=-0.39$ & $0.697^{c}$ \\
\hline
\end{tabular}

Values are means \pm standard errors unless otherwise stated.

${ }^{\text {a }}$ Student's t-test; ${ }^{\mathrm{b}}$ Chi-squared test; ${ }^{\mathrm{c}}$ Mann-Whitney U-test; ${ }^{\mathrm{d}}$ Fisher's exact test; ${ }^{*}$ Where applicable

Abbreviations: $\mathrm{ADS}=$ atypical depression supplement; $\mathrm{BMI}=$ body mass index, $\mathrm{BDI}=$ Beck Depression Inventory, HAM-D = Hamilton Depression Rating Scale, IL = interleukin, $\mathrm{MDD}=$ major depressive disorder; NSAID = non-steroidal anti-inflammatory drug

present study may have increased the risk of type II statistical errors, leading to the lack of detection of an actual difference in the cytokine levels between the study groups. Moreover, the studies of Pavón et al. (2006) [24] and Hernández et al. (2008) [41] represented patient populations and not a random cohort from a general population, and were thus more severely depressed. The mean HAM-D-21 score for the depressed group reported

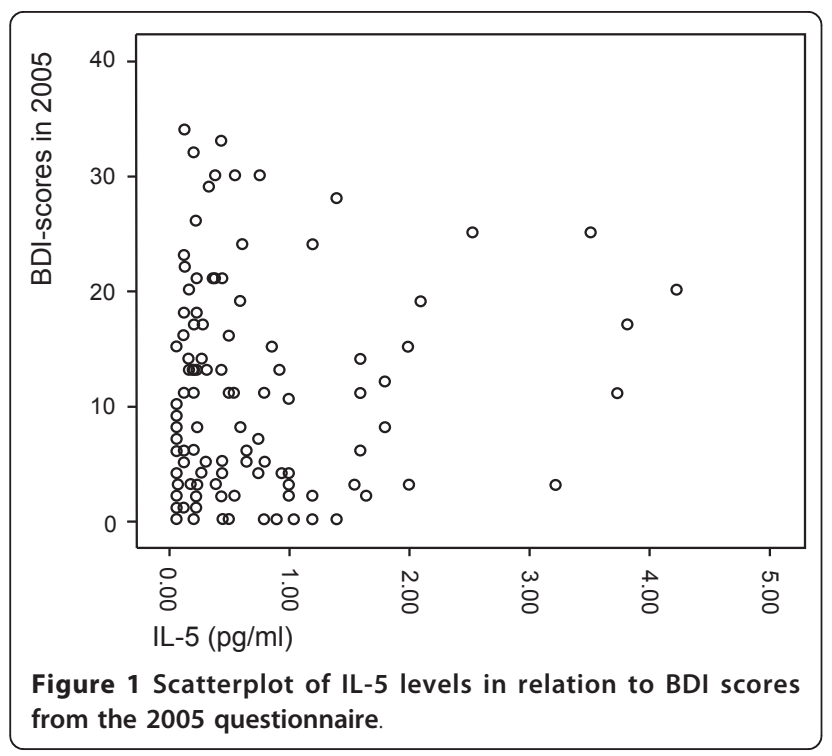

by Hernández et al. was 20.3, and the HAM-D-17 score in the study of Pavón et al. was 24.2, whereas in our MDD group the mean HAM-D-21 score was 12.0. Thus, cytokine differences are likely to be less pronounced in a population-based sample consisting of individuals with a depression score lower than those observed in patient samples.

In this study there was no significant relationship between MDD and asthma. Although there is very little

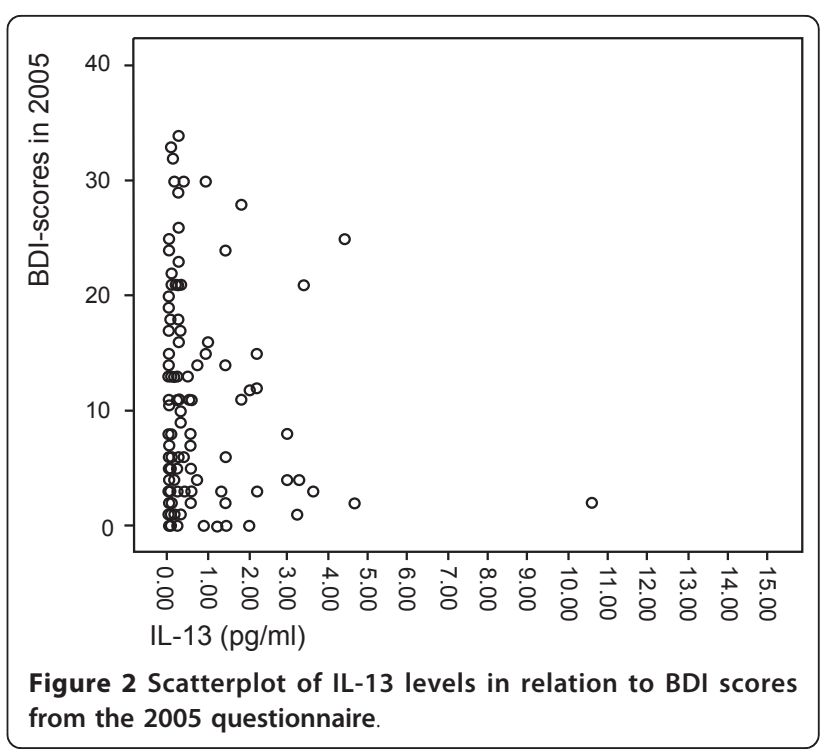




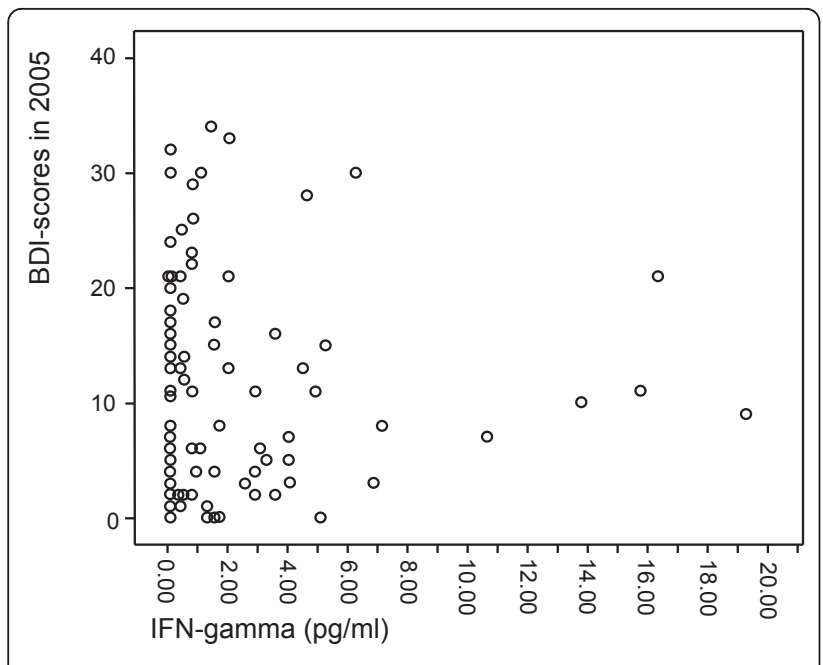

Figure 3 Scatterplot of IFN- $\gamma$ levels in relation to BDI scores from the 2005 questionnaire.

data covering the potential underlying mechanisms connecting asthma and MDD, Th2 cytokines appear to play a role in the pathophysiology of both of these diseases $[25,26,43]$, as asthma and other similar inflammatory diseases have been shown to increase the risk and symptoms of MDD [14].

\subsection{Possible mechanisms}

Peripheral cytokines can cross the blood-brain barrier, influencing complex brain functions both directly and indirectly [12,44]. Pavón et al. (2006) [24] hypothesized that the elevated circulatory cortisol levels associated with MDD could lead to abnormal patterns of synthesis and secretion of Th2 cytokines, thus provoking the depressive symptoms. This may involve several possible mechanisms.

Relatively little is known about IL-5. Most previous studies have not detected alterations in the levels IL-5 of MDD patients [42]. However, IL-5 activates several interesting signaling pathways, with activation of Januse kinase 2 (JAK) 2 and STAT5 being the most essential. The JAK-STAT pathways play important roles in cell proliferation and survival in both the CNS and the periphery through specific and diverse effects on cell responses to hormones, growth factors and cytokines $[45,46]$, while its activation can lead to depressive effects through glucocorticoid signaling [47]. IFN- $\alpha$ and $-\gamma$ have also been shown to activate JAK family kinases and consequently phosphorylate STATs [48], and further induce depressive symptoms [49]. In addition to JAK-STAT pathways, IL-5 uses the Ras GTPase-extracellular signalregulated kinase (Ras-ERK) pathway. IL-5 can activate the Ras-ERK pathway [50], which controls neural stem cell functions and maintains specific brain structures
[51]. Hyperactivity of Ras-ERK pathways has been observed to cause deficits in synaptic plasticity and hippocampus-related learning in mice [52]. Such mechanisms may play a role in depression. Thus, the elevated levels of IL-5 could be one of the factors inducing a depression-related decrease in central nervous system plasticity.

\subsection{Strengths and limitations}

One of our strengths in this study was the comprehensive evaluation of depressive symptomatology. In evaluating and diagnosing MDD, we used the Structured Clinical Interview for DSM-IV, as well as self-reported and interviewer-rated depression scales. Moreover, several factors such as antidepressant use [53], lifestyle factors [39,40], and various somatic medications and diseases such as asthma [14] affect the levels of cytokines expressed in circulation. Nevertheless, we were able to examine the effects of these potential confounders on our findings, even though the somatic conditions were self-reported. The depressed subjects in the present study suffered homogeneously from MDD, while those with bipolar disorder were excluded. The study population also solely consisted of individuals of Finnish descent, thus minimizing the potential confounding effect of genetic variation on our findings. The main limitation of our study was the small sample size, increasing the risk of type II statistical errors, which might have resulted in the lack of detection of actual significant differences between the groups. The high interassay variation in analysis could have also interfered with the ability to detect differences in cytokine levels. Secondly, due to the cross-sectional study design, we were unable to assess causality or confirm previous suggestions of possible biological routes. A fairly large number of conditions affect serum IL-5 levels, and despite statistical adjustment for known confounders, there remains the potential for residual confounding. Thirdly, we did not have data on some somatic conditions related to the secretion of some of the measured cytokines (e.g. allergic rhinitis, atopic dermatitis), which may have affected our findings. IL-13 may be associated with allergic rhinitis when the individuals are provoked with an allergen [54]. However, some data are available suggesting that the levels of IL-5 and IFN- $\gamma$ are unaffected even in the presence of an allergen [54]. Furthermore, to the best of our knowledge, these conditions are not clearly associated with MDD; thus, it is unlikely that these individuals would specifically concentrate in the MDD group. Lastly, a general guideline indicates that the number of non-detectable samples can be considered small when they comprise less than $30 \%$ of the total sample size [38]. In this study, the proportions of non-detectable samples for IL- 5 and IL-13 were below the $30 \%$ limit, but IFN- $\gamma$ exceeded this limit. However, 
Table 2 The likelihood for belonging to the major depressive disorder group.

\begin{tabular}{|c|c|c|c|c|c|c|c|c|c|c|c|c|c|c|c|c|c|c|c|c|c|c|}
\hline & \multirow[b]{2}{*}{ Model } & \multirow[b]{2}{*}{ OR } & \multicolumn{2}{|c|}{ Age } & \multicolumn{3}{|c|}{ Gender } & \multicolumn{3}{|c|}{ Marital status } & \multicolumn{3}{|c|}{ Daily smoking } & \multicolumn{3}{|c|}{ Alcohol use } & \multicolumn{3}{|c|}{ Cytokine* } & \multicolumn{3}{|c|}{$\begin{array}{c}\text { Additional covariate (antidepressant/ } \\
\text { NSAIDs/asthma) }\end{array}$} \\
\hline & & & $P$ & $\mathrm{Cl} 95 \%$ & OR & $p$ & $\mathrm{Cl} 95 \%$ & OR & $p$ & $\mathrm{Cl} 95 \%$ & OR & $p$ & $\mathrm{Cl} 95 \%$ & OR & $p$ & $\mathrm{Cl} 95 \%$ & OR & $p$ & $\mathrm{Cl} 95 \%$ & OR & $p$ & $\mathrm{Cl} 95 \%$ \\
\hline \multirow[t]{4}{*}{ IL-5* } & $1 .^{a}$ & 1.03 & 0.24 & $0.98-1.08$ & 1.37 & 0.49 & $0.56-3.35$ & 4.05 & 0.67 & $0.91-17.96$ & 7.95 & 0.001 & $2.34-27.03$ & 1.62 & 0.40 & $0.52-5.04$ & 1.76 & 0.04 & $1.03-2.99$ & - & - & - \\
\hline & $2 .^{b}$ & 1.01 & 0.69 & $0.96-1.06$ & 1.51 & 0.41 & $0.56-4.06$ & 4.23 & 0.85 & $0.82-21.76$ & 10.59 & 0.001 & $2.87-39.15$ & 2.32 & 0.18 & $0.68-7.88$ & 2.06 & 0.013 & $1.16-3.64$ & 11.98 & 0.001 & $3.25-44.16$ \\
\hline & 3. ${ }^{\mathrm{c}}$ & 1.04 & 0.15 & 0.99-1.09 & 1.30 & 0.58 & $0.52-3.30$ & 3.99 & 0.076 & $0.87-18.39$ & 9.08 & 0.001 & $2.60-31.73$ & 1.94 & 0.29 & $0.57-6.53$ & 1.89 & 0.022 & $1.10-3.27$ & 0.084 & 0.033 & $0.01-0.82$ \\
\hline & 4. ${ }^{d}$ & 1.03 & 0.24 & $0.98-1.08$ & 1.31 & 0.56 & $0.53-3.25$ & 3.80 & 0.81 & $0.85-17.01$ & 8.60 & 0.001 & $2.46-30.09$ & 1.67 & 0.38 & $0.54-5.17$ & 1.83 & 0.028 & $1.07-3.14$ & 2.45 & 0.30 & $0.45-13.43$ \\
\hline \multirow[t]{4}{*}{ IL-13* } & $1^{\text {a }}$ & 1.03 & 0.23 & 0.98-1.08 & 1.26 & 0.61 & $0.52-3.03$ & 4.50 & 0.044 & $1.04-19.50$ & 7.51 & 0.001 & $2.22-25.33$ & 1.47 & 0.50 & $0.48-4.50$ & 1.08 & 0.22 & $0.96-1.22$ & - & - & - \\
\hline & $2 .^{b}$ & 1.01 & 0.69 & $0.96-1.06$ & 1.30 & 0.59 & $0.50-3.36$ & 4.49 & 0.066 & $0.91-22.24$ & 9.24 & 0.001 & $2.54-33.58$ & 2.02 & 0.26 & $0.60-6.84$ & 1.06 & 0.33 & $0.94-1.20$ & 0.098 & 0.001 & $0.027-0.35$ \\
\hline & 3. ${ }^{c}$ & 1.04 & 0.15 & 0.99-1.09 & 1.19 & 0.71 & $0.48-2.94$ & 4.35 & 0.054 & $0.97-19.47$ & 8.36 & 0.001 & $2.41-29.07$ & 1.70 & 0.39 & $0.51-5.63$ & 1.09 & 0.186 & $0.96-1.24$ & 0.095 & 0.039 & $0.10-0.89$ \\
\hline & 4. ${ }^{d}$ & 1.03 & 0.22 & $0.98-1.08$ & 1.20 & 0.69 & $0.49-2.91$ & 4.24 & 0.055 & $0.97-18.54$ & 8.18 & 0.001 & $2.35-28.52$ & 1.47 & 0.50 & $0.48-4.50$ & 1.10 & 0.14 & $0.97-1.24$ & 2.65 & 0.29 & $0.44-15.87$ \\
\hline \multirow[t]{4}{*}{$\overline{\mathrm{IFN}-\gamma^{*}}$} & 1. ${ }^{\mathrm{a}}$ & 1.03 & 0.21 & $0.98-1.08$ & 1.32 & 0.54 & $0.55-3.19$ & 3.92 & 0.069 & $0.90-17.09$ & 7.41 & 0.001 & $2.19-25.14$ & 1.61 & 0.42 & $0.51-5.05$ & 1.02 & 0.23 & $0.99-1.05$ & - & - & - \\
\hline & 2..$^{b}$ & 1.01 & 0.66 & $0.96-1.06$ & 1.31 & 0.57 & $0.51-3.40$ & 3.86 & 0.094 & $0.80-18.74$ & 8.95 & 0.001 & $2.46-32.47$ & 2.15 & 0.23 & $0.62-7.41$ & 1.01 & 0.22 & $0.99-1.04$ & 0.10 & 0.001 & $0.029-0.37$ \\
\hline & 3. ${ }^{c}$ & 1.04 & 0.15 & 0.99-1.09 & 1.22 & 0.67 & $0.49-3.02$ & 4.18 & 0.062 & $0.93-18.85$ & 8.04 & 0.001 & $2.32-27.83$ & 1.74 & 0.37 & $0.52-5.80$ & 1.02 & 0.25 & $0.99-1.05$ & 0.11 & 0.053 & $0.011-1.03$ \\
\hline & $4 .^{d}$ & 1.03 & 0.21 & $0.98-1.08$ & 1.28 & 0.59 & $0.53-3.11$ & 3.77 & 0.078 & $0.86-16.49$ & 7.63 & 0.001 & $2.23-26.16$ & 1.61 & 0.41 & $0.52-5.05$ & 1.02 & 0.23 & $0.99-1.05$ & 1.72 & 0.52 & $0.33-8.88$ \\
\hline
\end{tabular}

a Covariates for Model 1: gender, age, marital status, daily smoking, and alcohol use

${ }^{b}$ Covariates for Model 2: gender, age, marital status, daily smoking, alcohol use, and antidepressant use

'Covariates for Model 3: gender, age, marital status, daily smoking, alcohol use, and NSAIDs use

${ }^{\mathrm{d}}$ Covariates for Model 4: gender, age, marital status, daily smoking, alcohol use, and diagnosis of asthma 
since all the imputed values were close to zero, the effect of the imputation method on the total variance is likely to have been very small.

\section{Conclusions}

We have been able to demonstrate that an increased likelihood of MDD was associated with elevated levels of IL-5. Elevated IL-5, which uses the neural plasticityrelated RAS-ERK pathway to mediate its actions in the CNS, could be one of the factors underlying depressionrelated changes in CNS plasticity. Further studies are needed to more thoroughly understand the exact biological mechanisms through which IL-5 is linked to depression

\section{Acknowledgements}

KH has received research support from Kuopio University Hospital EVO funding. HK-H was supported by the Academy of Finland (grant 116996). $\mathrm{K}$-HH was supported by a fellowship from the Academy of Finland. These funding bodies had no role in the study design; in the collection, analysis, or interpretation of data; in the writing of the manuscript; or in the decision to submit the manuscript for publication. A-PE, LN, JH, HV, MV-K, ITH and SML report no funding sources for this study. The authors thank Anne Huotari, MSc, Kaisa Haatainen, PhD, and Tarja Saharinen, MNSc, for their valuable contribution to the KUDEP Study.

\section{Author details}

'Department of Psychiatry, Kuopio University Hospital and University of Eastern Finland, Kuopio, Finland. ${ }^{2}$ Central Hospital of Central Finland, Jyväskylä, and University of Eastern Finland, Kuopio, Finland. ${ }^{3}$ Institute of Biomedicine, Division of Physiology and Biocenter Oulu, University of Oulu, Finland. ${ }^{4}$ Department of Clinical Medicine, University of Oulu, Finland. ${ }^{5}$ Department of Psychiatry, Lapland Hospital District, Rovaniemi, Finland. ${ }^{6}$ Kuopio Psychiatric Center, Kuopio, Finland. ${ }^{7}$ Department of Dermatology, Kuopio University Hospital and University of Eastern Finland, Kuopio, Finland.

\section{Authors' contributions}

A-PE analyzed and interpreted the data, and drafted the manuscript. LN participated in the conception and design of the study and interpreted the data. $\mathrm{K}-\mathrm{HH}, \mathrm{HV}, \mathrm{JH}, \mathrm{KH}$, and $\mathrm{HK}-\mathrm{H}$ participated in the conception of the study, and the acquisition and interpretation of the data. MV-K and ITH participated in the conception of the study and data interpretation. SML participated in the conception and design of the study, analyzed the data and supervised the drafting of the manuscript. All the authors have revised the manuscript for important intellectual content, and have read and approved the final manuscript.

\section{Competing interests}

The authors declare that they have no competing interests.

Received: 25 August 2011 Accepted: 9 January 2012 Published: 9 January 2012

\section{References}

1. Maes M, Smith R, Scharpe S: The monocyte-T-lymphocyte hypothesis of major depression. Psychoneuroendocrinology 1995, 20:111-116.

2. Nadjar A, Bluthé RM, May MJ, Dantzer R, Parnet P: Inactivation of the cerebral NFkappaB pathway inhibits interleukin-1beta-induced sickness behavior and c-Fos expression in various brain nuclei. Neuropsychopharmacology 2005, 30:1492-1499.

3. Capuron L, Pagnoni G, Demetrashvili MF, Lawson DH, Fornwalt FB, Woolwine B, Berns GS, Nemeroff CB, Miller AH: Basal ganglia hypermetabolism and symptoms of fatigue during interferon-alpha therapy. Neuropsychopharmacology 2007, 32:2384-2392.
4. Capuron L, Pagnoni G, Demetrashvili M, Woolwine BJ, Nemeroff CB, Berns GS, Miller AH: Anterior cingulate activation and error processing during interferon-alpha treatment. Biol Psychiatry 2005, 58:190-196.

5. McAfoose J, Baune BT: Evidence for a cytokine model of cognitive function. Neurosci Biobehav Rev 2009, 33:355-366.

6. Nelson T, Ur C, Gruol D: Chronic interleukin-6 exposure alters electrophysiological properties and calcium signaling in developing cerebellar purkinje neurons in culture. J Neurophysiol 2002, 88:475-486.

7. Pace TWW, Hu F, Miller AH: Cytokine-effects on glucocorticoid receptor function: Relevance to glucocorticoid resistance and the pathophysiology and treatment of major depression. Brain Behav Immun 2007, 21:9-19.

8. Irwin MR, Miller AH: Depressive disorders and immunity: 20 years of progress and discovery. Brain Behav Immun 2007, 21:374-383.

9. Khairova RA, Machado-Vieira R, Du J, Manji HK: A potential role for proinflammatory cytokines in regulating synaptic plasticity in major depressive disorder. Int I Neuropsychopharmacol 2009, 12:561-578.

10. Myint AM, Leonard BE, Steinbusch HW, Kim YK: Th1, Th2, and Th3 cytokine alterations in major depression. J Affect Disord 2005, 88:167-173.

11. Zorrilla EP, Luborsky L, McKay JR, Rosenthal R, Houldin A, Tax A, McCorkle R, Seligman DA, Schmidt K: The relationship of depression and stressors to immunological assays: A meta-analytic review. Brain Behav Immun 2001, 15:199-226.

12. Raison $C L$, Capuron $L$, Miller Ah: Cytokines sing the blues: Inflammation of the pathogenesis of major depression. Trend Immunol 2006, 27:24-31.

13. Timonen M, Jokelainen J, Hakko H, Silvennoinen-Kassinen S, MeyerRochow VB, Herva A, Rasanen P: Atopy and depression: results from the Northern Finland 1966 birth cohort study. Mol Psychiatry 2003, 8:738-744.

14. Katon W: Asthma, suicide risk and psychiatric comorbidity. Am J Psychiatry 2010, 167:1020-1022.

15. Parkin J, Cohen B: An overview of the immune system. Lancet 2001, 357:1777-1789.

16. Hendrix S, Nitsch R: The role of Thelper cells in neuroprotection and regeneration. J Neuroimmunol 2007, 184:100-112.

17. Schroder K, Hertzog PJ, Ravasi T, Hume DA: Interferon-gamma: an overview of signals, mechanisms and functions. J Leukoc Biol 2004, 75:163-189.

18. Kim YK, Na KS, Shin KH, Jung HY, Choi SH, Kim JB: Cytokine imbalance in the pathophysiology of major depressive disorder. Prog NeuroPsychopharmacol Biol Psychiatry 2007, 31:1044-1053.

19. Szabo SJ, Kim ST, Costa GL, Zhang X, Fathman CG, Glimcher LH: A novel transcription factor, T-bet, directs Th1 lineage commitment. Cell 2000, 100:655-669.

20. Awasthi A, Murugaiyan G, Kuchroo VK: Interplay between effector Th17 and regulatory T cells. J Clin Immunol 2008, 28:660-670.

21. TomasiakŁozowska MM, Bodzentałukaszyk A, Tomasiak M, Skiepko R, Zietkowski Z: The role of interleukin 13 and interleukin 5 in asthma. Postepy Hig Med 2010, 64:146-155.

22. Zhu W, Liu N, Zhao Y, Jia H, Cui B, Ning G: Association analysis of polymorphisms in IL-3, IL-4, IL-5, IL-9, and IL-13 with Graves' disease. $J$ Endocrinol Invest 2010, 33:751-755.

23. Levine SJ, Wenzel SE: Narrative review: the role of Th2 immune pathway modulation in the treatment of severe asthma and its phenotypes. Ann Intern Med 2010, 152:232-237.

24. Pavón L, Sandoval-López G, Eugenia Hernández M, Loría F, Estrada I, Pérez M, Moreno J, Avila U, Leff P, Antón B, Heinze G: Th2 cytokine response in Major Depressive Disorder patients before treatment. J Neuroimmunol 2006, 172:156-165.

25. Cheng P, Huang K, Zhou G, Zeng Z, Wang T, Li B, Wang Y, He L, Feng G, Shi Y: Common SNPs in CSF2RB are associated with major depression and schizophrenia in the Chinese Han population. World J Biol Psychiatry 2011, 12:233-238.

26. Shelton RC, Claiborne J, Sidoryk-Wegrzynowicz M, Reddy R, Aschner M, Lewis DA, Mirnics K: Altered expression of genes involved in inflammation and apoptosis in frontal cortex in major depression. Mol Psychiatry 2011, 16:751-762.

27. Viinamäki H, Heiskanen T, Lehto SM, Niskanen L, Koivumaa-Honkanen $H$, Tolmunen T, Honkalampi K, Saharinen T, Haatainen K, Hintikka J: Association of depressive symptoms and metabolic syndrome in men. Acta Psychiatr Scand 2009, 120:23-29. 
28. Honkalampi K, Koivumaa-Honkanen H, Lehto SM, Hintikka J, Haatainen K, Rissanen T, Viinamäki $\mathrm{H}$ : Is alexithymia a risk factor for major depression, personality disorder, or alcohol use disorders? A prospective populationbased study. J Psychosom Res 2010, 68:269-273.

29. Beck AT, Ward CH, Mendelson M, Mock J, Erbaugh J: An inventory for measuring depression. Arch Gen Psychiatry 1961, 4:561-571.

30. American Psychiatric Association: Diagnostic and Statistical Manual of Mental Disorders (4th edn) (DSM-IV) Washington, D.C.: American Psychiatric Publishing; 1994

31. First MB, Spitzer RL, Gibbon M, Gibbon W, Janet BW: Structured Clinical Interview for DSM-IV-TR Axis I Disorders, Research Version, Non-patient Edition. (SCID-I/NP) New York: New York State Psychiatric Institute; 2002.

32. First MB, Gibbon M, Spitzer RL, Williams JBW, Benjamin LS: Structured Clinical Interview for DSM-IV Axis II Personality Disorders, (SCID-II) Washington, D.C.: American Psychiatric Press; 1997.

33. Williams JBW, Terman M: Structured interview guide for the Hamilton Depression Rating Scale with Atypical Depression Supplement (SIGH-ADS) New York: New York State Psychiatric Institute; 2003.

34. de Jager W, te Velthuis H, Prakken BJ, Kuis W, Rijkers GT: Simultaneous Detection of 15 Human Cytokines in a Single Sample of Stimulated Peripheral Blood Mononuclear. Cells Clin Diagn Lab Immunol 2003, 10:133-139.

35. Elshal MF, McCoy JP: Multiplex bead array assays: performance evaluation and comparison of sensitivity to ELISA. Methods 2006, 38:317-323.

36. Leng SX, McElhaney JE, Walston JD, Xie D, Fedarko NS, Kuchel GA: ELISA and multiplex technologies for cytokine measurement in inflammation and aging research. J Gerontol A Biol Sci Med Sci 2008, 63:879-884.

37. Gottschalk PG, Dunn JR: The Five Parameter Logistic: A Characterization and Comparison with the Four-Parameter Logistic. Analytical Biochemistry 2005, 343:54-65.

38. Uh HW, Hartgers FC, Yazdanbakhsh M, Houwing-Duistermaat JJ: Evaluation of regression methods when immunological measurements are constrained by detection limits. BMC Immunol 2008, 9:59.

39. González-Quintela A, Vidal C, Lojo S, Pérez LF, Otero-Antón E, Gude F, Barrio E: Serum cytokines and increased total serum IgE in alcoholics. Ann Allergy Asthma Immunol 1999, 83:61-67.

40. Tsunoda M, Tsunoda H, Guevarra L, Tollerud DJ: The relation between serum cytokine levels and common laboratory tests in healthy Japanese males. Environ Health Prev Med 2003, 8:6-12.

41. Hernández ME, Mendieta D, Martínez-Fong D, Loría F, Moreno J, Estrada I, Bojalil R, Pavón L: Variations in circulating cytokine levels during 52 week course of treatment with SSRI for major depressive disorder. Eur Neuropsychopharmacol 2008, 18:917-924.

42. Simon NM, McNamara K, Chow CW, Maser RS, Papakostas Gl, Pollack MH, Nierenberg AA, Fava M, Wong KK: A detailed examination of cytokine abnormalities in Major Depressive Disorder. Eur Neuropsychopharmacol 2008, 18:230-233.

43. Bhakta NR, Woodruff PG: Human asthma phenotypes: from the clinic, to cytokines, and back again. Immunol Rev 2011, 242:220-232.

44. Banks W: Blood-Brain Barrier Transport of Cytokines: A Mechanism for Neuropathology. Current Pharmaceutical Design 2005, 11:973-984.

45. Heim MH: The Jak-STAT pathway: specific signal transduction from the cell membrane to the nucleus. Eur J Clin Invest 1996, 26:1-12.

46. Zambrano A, Otth C, Maccioni RB, Concha II: IL-3 control TAU modifications and protects cortical neurons from neurodegeneration. Curr Alzheimer Res 2010, 7:615-624.

47. Hu F, Pace TW, Miller AH: Interferon-alpha inhibits glucocorticoid receptor-mediated gene transcription via STAT5 activation in mouse HT22 cells. Brain Behav Immun 2009, 23:455-463.

48. Darnell JE Jr, Kerr IM, Stark GR: Jak-STAT pathways and transcriptional activation in response to IFNs and other extracellular signaling proteins. Science 1994, 264:1415-1421.

49. Felger JC, Alagbe O, Hu F, Mook D, Freeman AA, Sanchez MM, Kalin NH, Ratti E, Nemeroff CB, Miller AH: Effects of interferon-alpha on rhesus monkeys: a nonhuman primate model of cytokine-induced depression. Biol Psychiatry 2007, 62:1324-1333.

50. Yoshimura A: Regulation of cytokine signaling by the SOCS and Spred family proteins. Keio J Med 2009, 58:78-83.

51. Phoenix TN, Temple S: Spred1, a negative regulator of Ras-MAPK-ERK, is enriched in CNS germinal zones, dampens NSC proliferation, and maintains ventricular zone structure. Genes Dev 2010, 24:45-56.
52. Denayer E, Ahmed T, Brems H, Van Woerden G, Borgesius NZ, CallaertsVegh Z, Yoshimura A, Hartmann D, Elgersma Y, D'Hooge R, Legius E, Balschun D: Spred1 is required for synaptic plasticity and hippocampusdependent learning. J Neurosci 2008, 28:14443-14449.

53. Sutcigil L, Oktenli C, Musabak U, Bozkurt A, Cansever A, Uzun O, Sanisoglu SY, Yesilova Z, Ozmenler N, Ozsahin A, Sengul A: Pro- and antiinflammatory cytokine balance in major depression: effect of sertraline therapy. Clin Dev Immunol 2007, 7639-7646.

54. KleinJan A, Dijkstra MD, Boks SS, Severijnen LA, Mulder PG, Fokkens WJ: Increase in IL-8, IL-10, IL-13, and RANTES mRNA levels (in situ hybridization) in the nasal mucosa after nasal allergen provocation. $\mathcal{J}$ Allergy Clin Immunol 1999, 103:441-450.

\section{Pre-publication history}

The pre-publication history for this paper can be accessed here: http://www.biomedcentral.com/1471-244X/12/2/prepub

doi:10.1186/1471-244X-12-2

Cite this article as: Elomaa et al:: Elevated levels of serum IL-5 are associated with an increased likelihood of major depressive disorder. BMC Psychiatry 2012 12:2.

\section{Submit your next manuscript to BioMed Central and take full advantage of:}

- Convenient online submission

- Thorough peer review

- No space constraints or color figure charges

- Immediate publication on acceptance

- Inclusion in PubMed, CAS, Scopus and Google Scholar

- Research which is freely available for redistribution 